\title{
IDENTIFICAÇÃO DE ÁREAS DO USO, COBERTURA E OCUPAÇÃO DA TERRA NO BAIXO CURSO DA BACIA HIDROGRÁFICA DO RIO CACHOEIRA, NO SUL DA BAHIA
}

\author{
AUTOR: GABRIEL MARTINEZ TOLENTINO \\ CO-AUTOR/ORIENTADOR: VINICIUS DE AMORIM SILVA
}

Resumo: O objetivo desse trabalho foi analisar as transformações no uso, cobertura e ocupação da terra no baixo curso da bacia hidrográfica do rio Cachoeira (BHRC) nos anos de 1986, 1994 e 2017. Para atingir o objetivo do trabalho utilizou-se de técnicas de Geoprocessamento como obtenção, tratamento e manipulação de dados espaciais da área de estudo. Para isso empregou-se o software QGIS versão 3.10.7 para a caracterização do uso, cobertura e ocupação da terra. Utilizou-se também, técnicas de tratamento digital, das Imagens orbitais LandSat-5 e LandSat-8. Para isso, foram determinadas as classes de uso e cobertura e ocupação da terra: 1) Mata, 2) Cabruca, 3) Capoeira, 4) Pastagem, 5) Área Urbana, e: 6) Corpos d'água. Posteriormente foram coletadas amostras de pixels no plugin SCP do software QGIS, para viabilizar distinção das classes determinadas previamente, aplicou-se o algoritmo Máxima Verossimilhança. Ao comparar os resultados, verificou-se a predominância da pastagem, a diminuição da classe Cabruca, e um aumento na Área Urbana. O uso de técnicas de sensoriamento remoto por meio do software de domínio público QGIS associado a validação de dados por classificação supervisionada no campo, se mostrou eficaz para a análise multitemporal e espacial da área de estudo.

Palavras-chave: Gestão territorial, dinâmica da paisagem, análise espacial. 